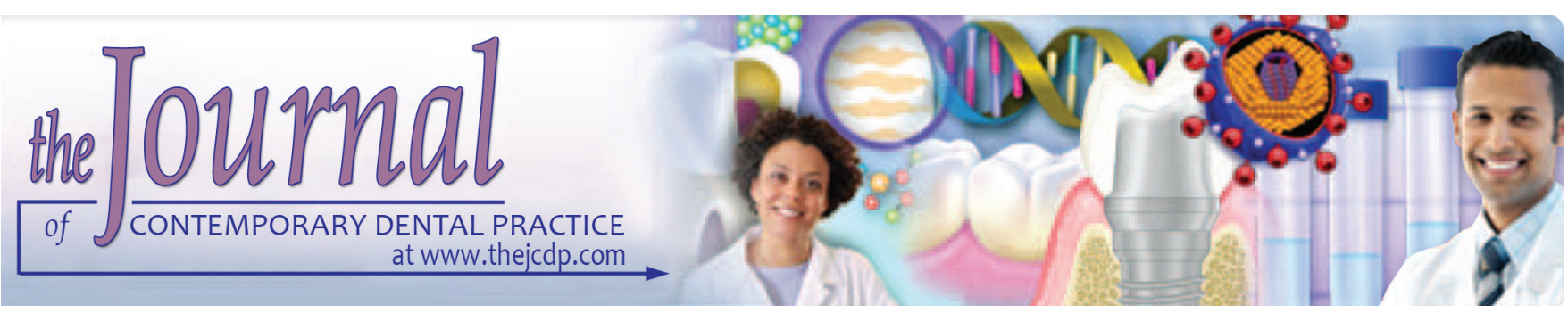

\title{
Golden Proportion Analysis of Dental-Skeletal Patterns of Class II and III Patients Pre and Post Orthodontic-orthognathic Treatment
}

${ }^{1}$ Fernanda P Bragatto, ${ }^{2}$ Mariliani Chicarelli, ${ }^{3}$ Amanda VB Kasuya, ${ }^{4}$ Wilton M Takeshita, ${ }^{5}$ Liogi Iwaki-Filho, ${ }^{6}$ Lilian CV Iwaki

\begin{abstract}
Introduction: The golden proportion has been used in dentistry in an attempt to improve facial function and, possibly, esthetics by simplifying the diagnosis of facial and dental disharmony. The aim of this study is to analyze pre- and postoperative cephalometric tracings of lateral cephalograms of patients with class II and III deformities submitted to orthognathic surgery, and verify if the 13 dental-skeletal patterns (ratios), as defined by Ricketts, moved closer to or further away from the golden proportion.
\end{abstract}

Materials and methods: A total of 110 lateral cephalometric radiographs, 55 obtained preoperatively and 55 postoperatively, were analyzed using Dolphin Imaging software.

Results: Radiographs analysis demonstrated that ratios 1, 3, $4,5,7,8,9,10$, and 13 remained statistically different from the golden proportion postoperatively. Ratio 12 was the only one to move closer to the golden number, while the opposite happened with ratio 6 , which moved further away after the surgery. Ratios 2 and 11 kept statistically similar to the golden proportion both pre and postoperatively.

Conclusion: It may be concluded that orthognathic surgery had little effect on the proportions studied, and that the golden proportion was not present in the majority of the ratios analyzed neither before nor after surgery.

\footnotetext{
${ }^{1}$ Department of Dentistry, State University of Maringá, Maringá Paraná, Brazil

${ }^{2,6}$ Department of Dentistry and Oral Radiology, State University of Maringá, Maringá, Paraná, Brazil

${ }^{3}$ Department of Restorative Dentistry and Dental Materials School of Dentistry, Federal University of Goiás, Goiânia, Goiás, Brazil

${ }^{4}$ Department of Dentistry and Oral Diagnosis, Federal University of Sergipe, São Cristóvão, Sergipe, Brazil

${ }^{5}$ Department of Dentistry, Oral, and Maxillofacial Surgery, State University of Maringá, Maringá, Paraná, Brazil

Corresponding Author: Lilian CV Iwaki, Department of Dentistry and Oral Radiology, State University of Maringá, Maringá, Paraná Brazil, Phone: +554430119051, e-mail: lilianiwaki@gmail.com
}

Clinical significance: Determine whether the facial patterns approach the golden ratio after surgical correction. Also determine whether the golden ratio may be a standard to guide the surgical treatment of patients with skeletal patterns of type II and III.

Keywords: Cephalometry, Face, Malocclusion angle class I, Malocclusion angle class II, Orthognathic surgery.

How to cite this article: Bragatto FP, Chicarelli M, Kasuya AVB, Takeshita WM, Iwaki-Filho L, Iwaki LCV. Golden Proportion Analysis of Dental-Skeletal Patterns of Class II and III Patients Pre and Post Orthodontic-orthognathic Treatment. J Contemp Dent Pract 2016;17(9):728-733.

Source of support: This work was supported by Fundação Araucária through the PIBIC/FA/UEM program for the concession of Scientific Initiation Grants.

Conflict of interest: None

\section{INTRODUCTION}

The so-called "Divine Proportion" or "Golden Proportion" is a mathematical relationship which is believed to express the universal harmony and, as such, the ideal measure to rule the symmetry and the proportions of the different elements of the human body. ${ }^{1}$ This mathematical relationship is obtained by the asymmetric division of a line in such a way that the greater part of this line is always 1.618 times the size of the smaller part, which corresponds to 0.618 times the length of the larger part., ${ }^{2,3}$ Thus, the golden proportion is expressed by the 1:1.618 ratio, represented by the Greek letter "phi." 3-5

In dentistry, Lombardi ${ }^{6}$ was the first to introduce the concept of "Golden Proportion," and later Levin" discussed the presence of the golden proportion in anterosuperior teeth. The golden proportion was popularized in orthodontics and oral surgery by Ricketts, ${ }^{2}$ who reported to repeatedly find the 1:1.618 ratio in a 
series of lateral and frontal cephalometric radiographs considered ideal by the author. Amoric ${ }^{8}$ also demonstrated the existence of the golden proportion in many cephalometric measurements at different stages of facial growth.

The golden proportion has been used in dentistry in an attempt to improve facial function and, possibly, esthetics by simplifying the diagnosis of facial and dental disharmony. ${ }^{9,10}$ Some authors have suggested that the esthetic appreciation of one's face seems to be related to facial structures following the golden proportion. ${ }^{11-13}$ However, this assumption has been controversial. In a comprehensive work that analyzed lateral and frontal cephalograms and pictures of patients, Baker and Woods ${ }^{14}$ assessed the role of the golden proportion in the improvement of facial esthetics of patients submitted to surgical and orthodontic treatments. The authors found that not only did the measured ratios often move away from the divine proportion rather than toward it, but also that an improvement in esthetics often took place even when a majority of the proportions were further away from the golden ratio after surgery. ${ }^{14}$

Thus, while some studies advocate that the golden proportion has a significant relationship with facial esthetics, others have demonstrated that the golden proportion is not a universal decisive factor for smiles and faces to be considered esthetic and pleasing. ${ }^{15-18}$ Scolozzi et $\mathrm{al}^{5}$ reported that the golden proportion of the face may only be predicted by specific cephalometric analysis, and that parameters, such as age, gender, and type of dentofacial deformities, as well as type of surgery may also significantly influence the final outcome in relation to the golden proportion. ${ }^{13}$

Discrepancies in bone development in the facial thirds may be considered esthetically unpleasing, and individuals with short or long faces present the risk of developing different types of disorders, which are frequently associated with cases of malocclusion class II and III. ${ }^{10,19}$ The divine proportion is still employed in orthodontic-orthognathic planning, ${ }^{20}$ and used as a guideline for the treatment in order to improve the facial esthetic balance and to correct biting. ${ }^{5}$ Ricketts, ${ }^{21}$ a strong advocator on the use of divine proportion as a guideline for the orthognathic surgery, suggested the use of 13 skeletal ratios in lateral and frontal radiographs, which should ideally follow the divine proportion in order to obtain a proportional and beautiful face. ${ }^{14}$ However, the assumption that corrections based on cephalometric standards lead to correct facial esthetics has been placed into question, as the soft tissue covering the teeth and bone may vary so greatly that the dentalskeletal pattern may be inadequate in evaluating facial harmony. 22,23
Presently, orthognathic surgery planning is frequently performed with the use of imaging software, based on the three-dimensional (3D) facial clinical analysis of the soft tissues as well as the study of cephalometry models. ${ }^{22,23}$ This method involves the analysis of the proportions existing between the facial thirds; the upper third from the tríquio to the glabella, the mid-third from the glabella to the subnasal, and the lower third from the subnasal to the mentonian. ${ }^{22,23}$ Nonetheless, it would be expected that patients with dentomaxillofacial class II and III deformities, submitted to orthognathic surgery based on the analysis of the soft tissues, should present changes in their dental-skeletal pattern. If these changes should represent an approximation to the golden proportion is still a matter of debate.

The objective of this study was, therefore, to analyze pre- and postoperative cephalometric tracings of lateral cephalograms of patients with dentomaxillofacial class II and III deformities submitted to orthognathic surgery, and verify whether patients' dental-skeletal patterns, as defined by Ricketts, ${ }^{2}$ moved closer to or further away from the golden proportion.

\section{MATERIALS AND METHODS}

This study was duly approved by the Institutional Review Board of the State University of Maringá (UEM), Brazil (decision no. 160.480/2012). This retrospective study was performed based on the records of patients submitted to orthodontic treatment followed by orthognathic surgery for dentomaxillofacial deformities selected from the Oral Radiology and Imaging Clinic of the State UEM between January 2006 and July 2014. The sample comprised 55 records of patients of both genders, mean age of 35 years and 7 months, with no craniofacial deformities, syndromes, or palatal fissures. A total of 110 lateral cephalometric radiographs, 55 obtained preoperatively and 55 postoperatively, were analyzed.

Facial planning for all patients was performed with the use of Dolphin Imaging software, version 11.7, according to the principles established by Arnett and Bergman (1993). ${ }^{22,23}$ All the orthognathic surgeries to correct dentomaxillofacial deformities class II and III were performed by the same professional. At the time of surgery, all the participating individuals signed a free term of consent, authorizing the disclosing of their radiographic and photographic documentation for teaching and research purposes. All the surgeries were considered successful in restoring class I function.

No unacceptable risks or discomfort were involved, as only radiographs filed with patients records were analyzed. All patient information was kept confidential. The radiographs were taken after the referral from a 
buccomaxillofacial surgery and traumatology expert, digitized and stored in the database at the Oral Radiology and Imaging Clinic UEM. All radiographs were standardized with cephalostat, with the Frankfurt plane of the head parallel to the horizontal plane, and the midsagittal plane perpendicular to the horizontal plane, with relaxed lips. Radiographs were digitized at $300 \mathrm{dpi}$ with no enlargement, and saved in TIFF format in a scanner with a transparency reader (HP Scanjet G4050, HewlettPackard, Washington, USA).

\section{Cephalometric Markings}

Radiographs taken pre and postoperatively were analyzed using Dolphin Imaging software, version 11.7 (Dolphin Imaging and Management Solutions, Chatsworth, Calif). Radiographs markings and analysis were individually conducted by the same examiner. Dental-skeletal patterns were assessed using the golden proportion based on the work of Ricketts. ${ }^{2}$ The 13 ratios assessed were:

1. Corpus axis length (1.618): Condylar axis length (1.0);

2. Basal or cranial anterior base length (CC to $N$ ): Distance from CC to Ar;

3. Length of the hard palate (ANSPNS): Distance from PNS to the posterior;

4. Distance from A to the anterior border of the mandible: Distance from the anterior border of the mandible to the outline of the pharynx;

5. Anterior length of $\mathrm{FH}$ ( $\mathrm{PtV}$ to Or): Distance from $\mathrm{PtV}$ to the glenoid fossa;

6. Facial axis length (CC to $\mathrm{Gn}$ ): Posterior facial height (CC to Go);

7. Lower facial axis (Gn to ANS-Xi line): Upper facial axis (the ANS-Xi line to CC);

8. Distance from SPog to A: Distance from A to FH;

9. Distance from Me to the palate at the incisive canal: Distance from the palate at the incisive canal to Ex;

10. Distance from SPog to Ii: Distance from Ii to A;

11. SN: S-Ba;

12. Ramus height (R3 to R4): Ramus depth (R1 to R2);

13. $\mathrm{PtV}$ to the mesial of the mandibular first molar: Mesial of the mandibular first molar to incision inferius.

With the intention of minimizing possible intraexaminer marking mistakes, i.e., method error, each measuring unit was marked twice, with an interval of 15 days between markings.

\section{Statistical Analysis}

To determine the minimum number of radiographs to be analyzed, G power test was performed with the power defined at $80 \%$, at a level of significance of $p>0.05$. The values obtained in the two markings were submitted to Pearson's correlation coefficient analysis.

The distribution of the final ratio data was verified with the Shapiro-Wilk test. The data were then submitted to the Student's t test (paired analysis) to verify if any difference in the mean ratio values between groups (pre and postoperatively) existed. Student's t test was used to compare the mean ratios (pre and postoperatively) to test the hypothesis and that the mean value of each ratio was 1.618033. All tests were conducted with a 5\% level of significance.

\section{RESULTS}

$G$ power test determined the minimum number of 34 radiographs for both parametric and nonparametric tests. Pearson's analysis demonstrated a correlation coefficient of 0.9976 between the data collected in the first and the second markings. As the correlation was almost perfect, only the data collected in the first markings were used.

The results obtained from the 13 ratios both pre and postoperatively were compared to the golden number (1.618) using Student's t test. Graph 1 illustrates the relationship of each ratio with the golden number, and compares the ratios obtained pre and postoperatively. When analyzing the preoperative radiographs, the values obtained for the ratios $1,3,4,5,7,8,9,10,12$, and 13 were found to be statistically different (far) from the golden number $(\mathrm{p}<0.5)$, while ratios $2(1.655 ; \mathrm{p}=0.26)$, $6(1.659 ; \mathrm{p}=0.124)$, and $11(1.559 ; 0.117)$ presented values considered statistically similar (close) to the golden proportion.

When the postoperative radiographs were analyzed, ratios $1,3,4,5,7,8,9,10$, and 13 remained statistically different (far) from the golden proportion $(\mathrm{p}<0.05)$. Ratio 12, which in the preoperative cephalometric measurements was statistically different(far) from the golden proportion (1.688; $\mathrm{p}=0.034)$, moved closer to the golden number after the surgical treatment and was no longer different $(1.645 ; \mathrm{p}=0.444)$. However, the opposite happened with ratio 6 , which in the preoperative measurements was close to the golden proportion but moved further away postoperatively, becoming statistically different (1.679; $\mathrm{p}=0.013)$. Ratios 2 and 11 remained statistically similar (close) to the golden proportion postoperatively $(\mathrm{p}>0.5)$.

When the ratios obtained before and after the orthodontic-orthognathic treatment were compared, only ratios $8(\mathrm{p}=0.04)$ and $9(\mathrm{p}=0.04)$ presented statistically significant differences. In both cases the ratios moved even further away from the golden proportion after the surgical treatment. 


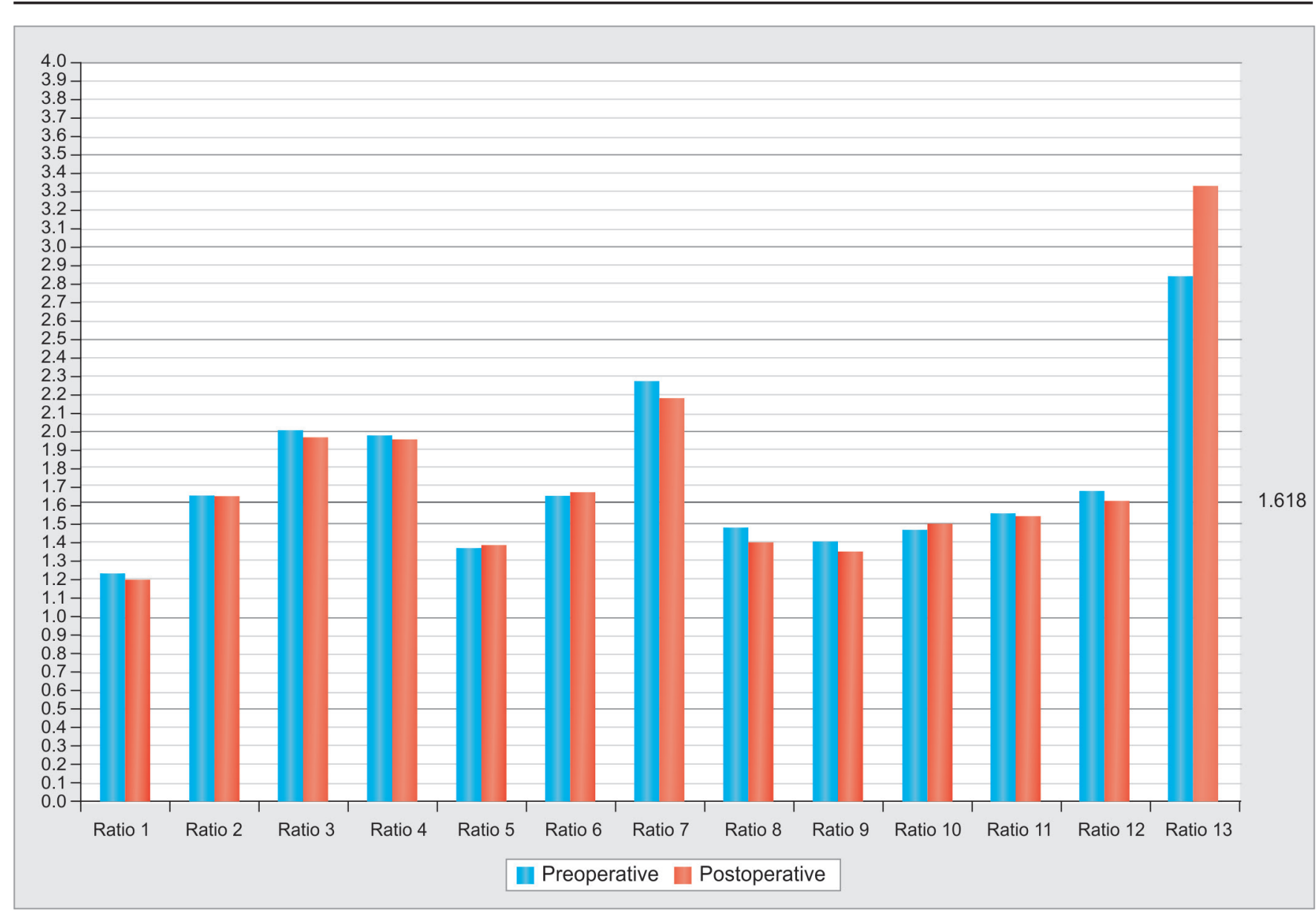

Graph 1: A comparative graph of the ratios assessed pre- and postoperatively in relation to the golden number (1.618)

\section{DISCUSSION}

The present study analyzed the relationship of cephalometric tracings as defined by Ricketts ${ }^{2}$ with the golden number (1.618), in two different occasions, before and after the surgical treatment for the correction of malocclusion class II and III with 3D facial planning. The results of the present study demonstrated that the ratios assessed hardly changed after the orthodontic-orthognathic treatment. The majority of the ratios assessed were statistically different (far) from the golden number both before and after the surgery, with only three of the 13 ratios $(2,6$, and 12) assessed demonstrating to be close to the golden proportion before surgery, and three $(2,11,12)$ after surgery (Graph 1).

Researchers from varied areas have been motivated to study the possibility of facial-skeletal measurements to be related with ideal proportions, ${ }^{24}$ so that esthetics may be scientifically assessed rather than based on subjective judgements. ${ }^{21,25}$ Jefferson $^{24}$ suggested that individuals' dental-skeletal parameters tend to develop according to the golden proportion, since it would be beneficial not only for esthetic reasons but also physiologically. However, dental and facial characteristics may differ and suffer genetic variations and environmental influences. ${ }^{14,24}$ Moreover, the perception of what is beautiful may also vary based on the geographical localization and the historical-cultural context of the region patients come from. ${ }^{26}$

In the present study, the 55 radiographs selected came from patients with dentomaxillofacial deformities class II and III submitted to orthodontic treatment and orthognathic surgery. Facial planning in all cases was performed with the use of the Dolphin Imaging software, based on the 3D facial clinical analysis of the soft tissues as well as cephalometry models according to the principles established by Arnett and Bergman. ${ }^{22,23}$ Thus, the golden proportion was not adopted as a guideline for the final result. The results demonstrated that after the surgical treatment had been completed, only ratio 11 moved closer and became statistically similar to the golden number, while ratio 6 moved further away. Scolozzi et $\mathrm{al}^{5}$ defended that the use of cephalometric analysis inspired on the divine proportion as a guideline for the production of proportional faces may only be effective in the lower third of the face. In contrast, however, Silva et $\mathrm{al}^{25}$ demonstrated that the lower facial third and the dental arches are less likely to be correlated to the golden proportion. Baker and Woods ${ }^{14}$ did not observe any correlation between the facial changes achieved by orthognathic surgery and the golden proportion, and suggested that 
the golden proportion may only be used in combination with other methods for cephalometric and facial assessment. In agreement with the work of Baker and Woods, ${ }^{14}$ the results found in this study also demonstrated that the ratios assessed were not significantly affected by the orthognathic surgery and remained statistically far from the golden proportion.

It is believed that individuals who undergo orthognathic surgery for dentomaxillofacial deformities should present more esthetic faces after the treatment. ${ }^{27}$ Additionally, people with attractive faces seem to present higher level of agreement with the golden proportion than those with common faces. ${ }^{4,12}$ Unfortunately, no visual records of the participating patients existed and, therefore, they could not be visually assessed before and after the surgical and orthodontic treatment, which is a limitation of this study. As a result, it was not possible to establish if these patients actually obtained more harmonious and beautiful faces after the treatment, ${ }^{12}$ preventing the establishment of a correlation between the facial measurements conducted with esthetic alterations. Nonetheless, esthetic guidelines based on 19 key traits were followed in determining the surgical orthodontic plan, so that normal facial traits were maintained while abnormal characteristics were corrected. ${ }^{22,23}$ Patient records indicate that all the orthognathic surgeries were successful in providing patients with class I function, and all patients reported to be satisfied with their final appearance. Although the divine proportion was not present in patients submitted to surgical treatments, previous investigations have already demonstrated that facial attractiveness in general does not depend on any preestablished standards. ${ }^{28,29}$ De Castro et $\mathrm{al}^{30}$ demonstrated that pleasant smiles were closer to the divine proportions, but they did not necessarily corresponded to them. The fact that the ratios 1, 3, $4,5,7,8,9,10$ and 13 kept statistically different from the golden proportion both pre- and postoperatively may be an indication that orthognathic surgery has little effect on the proportions studied.

Investigations have demonstrated that dental and smile proportions do not normally correlate with the golden proportion. ${ }^{31,32}$ Although several studies have assessed the presence of the golden proportion, the influence of tooth and/or face height and width on esthetics seems also to be important factors. ${ }^{33-35}$ This seems to suggest that beauty is more associated with symmetry and height and width relationships than with a mathematical proportion. ${ }^{33,36}$

\section{CONCLUSION}

Within the limitations of this study, and based on the 13 ratios measurements from lateral cephalograms of
55 class II and III patients before and after the orthognathic surgery, it may be concluded that the golden proportion was not present in the majority of the ratios analyzed preoperatively, and that they remained mostly unchanged after surgery.

\section{CLINICAL SIGNIFICANCES}

Determine whether the facial patterns approach the golden ratio after surgical correction. Also determine whether the golden ratio may be a standard to guide the surgical treatment of patients with skeletal patterns of type II and III.

\section{ACKNOWLEDGMENT}

Authors would like to thank Mr. Antonio Carlos Correa for his contribution with the English version of this paper.

\section{REFERENCES}

1. Wood TJ. Aesthetics and orthodontics. Dent Pract Dent Rec 1969 Mar;19(7):247-260.

2. Ricketts RM. The biologic significance of the divine proportion and Fibonacci series. Am J Orthod 1982 May;81(5):351-370.

3. Kim YH. Easy facial analysis using the facial golden mask. J Craniofac Surg 2007 May;18(3):643-649.

4. Ferring V, Pancherz H. Divine proportions in the growing face. Am J Orthod Dentofacial Orthop 2008 Oct;134(4):472-479.

5. Scolozzi P, Momjian A, Courvoisier D. Dentofacial deformities treated according to a dentoskeletal analysis based on the divine proportion: are the resulting faces de facto "divinely" proportioned? J Craniofac Surg 2011 Jan;22(1):147-150.

6. Lombardi RE. The principles of visual perception and their clinical application to denture esthetics. J Prosthet Dent 1973 Apr;29(4):358-382.

7. Levin EI. Dental esthetics and the golden proportion. J Prosthet Dent 1978 Sep;40(3):244-252.

8. Amoric M. The golden number: applications to cranio-facial evaluation. Funct Orthod 1995 Jan-Feb;12(1):18-21, 24-25.

9. Parnia F, Hafezeqoran A, Mahboub F, Moslehifard E, Koodaryan R, Moteyagheni R, Saleh Saber F. Proportions of maxillary anterior teeth relative to each other and to golden standard in tabriz dental faculty students. J Dent Res Dent Clin Dent Prospects 2010 Summer;4(3):83-86.

10. Singh R, Tripathi A, Singh S, Bhatnagar A. A study on the practical applicability of the rule of golden rectangle in dental aesthetics. Eur J Prosthodont Restor Dent 2011 Jun;19(2):85-89.

11. Jahanbin A, Basafa M, Alizadeh Y. Evaluation of the Divine Proportion in the facial profile of young females. Indian J Dent Res 2008 Oct-Dec;19(4):292-296.

12. Pancherz H, Knapp V, Erbe C , Heiss AM. Divine proportions in attractive and nonattractive faces. World J Orthod 2010 Spring;11(1):27-36.

13. Prokopakis EP, Vlastos IM, Picavet VA, Nolst Trenite G, Thomas R, Cingi C, Hellings PW. The golden ratio in facial symmetry. Rhinology 2013 Mar;51(1):18-21.

14. Baker BW, Woods MG. The role of the divine proportion in the esthetic improvement of patients undergoing combined orthodontic/orthognathic surgical treatment. Int J Adult Orthodon Orthognath Surg 2001;16(2):108-120. 
15. Cesario VA Jr, Latta GH Jr. Relationship between the mesiodistal width of the maxillary central incisor and interpupillary distance. J Prosthet Dent 1984 Nov;52(5):641-643.

16. Mahshid M, Khoshvaghti A, Varshosaz M, Vallaei N. Evaluation of "golden proportion" in individuals with an esthetic smile. J Esthet Restor Dent 2004;16(3):185-192.

17. Kiekens RM, Kuijpers-Jagtman AM, van'tHof MA, van'tHof BE, Maltha JC. Putative golden proportions as predictors of facial esthetics in adolescents. Am J Orthod Dentofacial Orthop 2008 Oct;134(4):480-483.

18. Jahanbin A, Poosti M, Salari S, Esmaily H, Sagha H. Effect of changes in divine proportion on esthetic perception of smile in frontal view. J Craniofac Surg 2013 Nov;24(6):1946-1949.

19. Packiriswamy V, Kumar P, Rao M. Identification of facial shape by applying golden ratio to the facial measurements: an interracial study in Malaysian population. N Am J Med Sci 2012 Dec;4(12):624-629.

20. Peron APLM, Morosini IC, Correia KR, Moresca R, Petrelli E. Photometric study of divine proportion and its correlation with facial attractiveness. Dental Press J Orthod 2012 Mar-Apr;17(2):124-131.

21. Ricketts RM. Divine proportion in facial esthetics. Clin Plast Surg 1982 Oct;9(4):401-422.

22. Arnett GW, Bergman RT. Facial keys to orthodontic diagnosis and treatment planning. Part I. Am J Orthod Dentofacial Orthop 1993 Apr;103(4):299-312.

23. Arnett GW, Bergman RT. Facial keys to orthodontic diagnosis and treatment planning - Part II. Am J Orthod Dentofacial Orthop 1993 May;103(5):395-411.

24. Jefferson Y. Facial beauty-establishing a universal standard. Int J Orthod Milwaukee 2004 Spring;15(1):9-22.

25. Silva MAS, Filho EM, Castilho JCM, Gil CTLA. Assessment of divine proportion in the cranial structure of individuals with Angle Class II malocclusion on lateral cephalograms. Dental Press J Orthod 2012 May-Jun;17(3):88-97.

26. Al-Marzok MI, Majeed KR, Ibrahim IK. Evaluation of maxillary anterior teeth and their relation to the golden proportion in Malaysian population. BMC Oral Health 2013 Jan 24;13:9.

27. Sinko K, Jagsch R, Benes B , Millesi G, Fischmeister F, Ewers R. Facial aesthetics and the assignment of personality traits before and after orthognathic surgery. Int J Oral Maxillofac Surg 2012 Apr;41(4):469-476.

28. Tatarunaite E, Playle R, Hood K, Shaw W, Richmond S. Facial attractiveness: a longitudinal study. Am J Orthod Dentofacial Orthop 2005 Jun;127(6):676-682.

29. Sunilkumar LN, Jadhav KS, Nazirkar G, Singh S, Nagmode PS, Ali FM. Assessment of facial golden proportions among north Maharashtrian population. J Int Oral Health 2013 Jun;5(3):48-54.

30. de Castro MV, Santos NC, Ricardo LH. Assessment of the "golden proportion" in agreeable smiles. Quintessence Int 2006 Sep;37(8):597-604.

31. Hasanreisoglu U, Berksun S, Aras K, Arslan I. An analysis of maxillary anterior teeth: facial and dental proportions. J Prosthet Dent 2005 Dec;94(6):530-538.

32. Ward DH. A study of dentists' preferred maxillary anterior tooth width proportions: comparing the recurring esthetic dental proportion to other mathematical and naturally occurring proportions. J Esthet Restor Dent 2007;19(6):324-337.

33. Michiels $G$, Sather AH. Validity and reliability of facial profile evaluation in vertical and horizontal dimensions from lateral cephalograms and lateral photographs. Int J Adult Orthodon Orthognath Surg 1994;9(1):43-54.

34. Rosenstiel SF, Rashid RG. Public preferences for anterior tooth variations: a web-based study. J Esthet Restor Dent 2002;14(2):97-106.

35. Raj V. Esthetic paradigms in the interdisciplinary management of maxillary anterior dentition-a review. J Esthet Restor Dent 2013 Oct;25(5):295-304.

36. Matoula S, Pancherz H. Skeletofacial morphology of attractive and nonattractive faces. Angle Orthod 2006 Mar;76(2): 204-210. 